\title{
Behavioural Sequences of Oviposition and Host-Feeding of Torymus (Syntomaspis) beneficus YASUMATSU et KAMIJO (Hymenoptera: Torymidae), a Native Parasitoid of Dryocosmus kuriphilus YASUMATSU (Hymenoptera: Cynipidae)
}

\author{
Yôzô MuraKamı and Eiji ToKuHISA \\ Institute of Biological Control, Faculty of Agriculture, \\ Kyushu University, Fukuoka 812, Japan
}

(Received August 14, 1984)

\begin{abstract}
Two laboratory experiments were carried out to determine the length of time required and the frequency of one oviposition and one host-feeding by the female of Torymus (Syntomaspis) beneficus, a native parasitoid of the chestnut gall wasp. One oviposition took an average of $820 \mathrm{sec}$. Host-feeding behaviour was observed twice in the second experiment, and took 3,870 and $1,300 \mathrm{sec}$, respectively. Construction of a feeding-tube for the host-feeding took 895 and 1,025 sec, respectively. Time-allocation for each component of a behavioural series differed between experiments depending on the age of the parasitoid females and/or other factors. The females selected galls for oviposition at substage $B$ and those at substage $C$, but were less interested in those at substage $A$. The rate of oviposition was 1.67 and 1.24 eggs per hour in the first and second experiments, respectively.
\end{abstract}

\section{INTRODUCTION}

Torymus (Syntomaspis) beneficus Yasumatsu et Kamijo is the only native parasitoid more or less synchronous with the chestnut gall wasp, Dryocosmus kuriphilus Yasumatsu in Japan (Murakami, 1981 a). Since the parasitoid also emerges from a leaf gall of Quercus serrata Thunberg formed by Andricus sp. (Yasumatsu and Kamijo, 1979) and has never been found in other Quercus galls, the authors suppose that Andricus sp. was the only native host of the parasitoid before the chestnut gall wasp entered Japan from China around 1941.

In Fukuoka, adults of $T$. (S.) beneficus emerge from March to early April from withered galls of D. kuriphilus and Andricus sp. formed the previous spring. The emergence of $50 \%$ of the females of the parasitoid is about 10 days earlier than the appearance of the Dryocosmus galls (Tokuhisa, 1979; Murakami, $1981 \mathrm{~b}$ ). Dissections of young Dryocosmus galls collected from the field from late March to the middle of April showed that eggs of the parasitoid were deposited on the inner wall of larval chambers in the galls, and invariably the Dryocosmus larvae in those chambers were already paralysed. This suggests that the parasitoid female paralysed the host larva at the time of depositing an egg. The interesting observation was also made that dead and withered larvae of D. kuriphilus were in the larval chambers where something like a feeding-tube was 
formed in the space between the withered cynipid larva and the chamber wall (Fig. 1). This phenomenon was believed to be evidence of the occurrence of host-feeding by the parasitoid female.

The present paper deals with laboratory experiments of the behavioural sequences of the oviposition and host-feeding of $T$. (S.) beneficus to determine the vulnerable stage of the host gall, the length of times required for one oviposition and one host-feeding as well as the frequency of the host-feeding incidence.

\section{MATERIALS AND METHODS}

Two laboratory experiments were carried out in the early spring of 1978 . Experiment I was made on March 22 in an insectary kept at a constant temperature of $25^{\circ} \mathrm{C}$ with an inseminated parasitoid female 9 day-old which had emerged from a chestnut gall collected in Mt. Aburayama, Fukuoka. After emergence, the female was kept in an incubator at a constant temperature of $10^{\circ} \mathrm{C}$ and $14 \mathrm{hr}$ light condition per day with honey and water. A twig was brought from a wild chestnut tree growing in the field which had, in advance, been covered with a nylon-gauze bag so as not to be parasitised. The twig was put in a flask. It bore 12 buds, of which the upper 7 (Nos. 1-7) were healthy and 5 others (Nos. 8-12) were galls in an early stage (Fig. 3, right).

The early stage of the gall was divided into three categories or substages: substage $A$ being the state where the gall has just begun to grow and remains largely covered with bud scales, substage $B$ being the state where the gall is further grown and is covered with scales only on its basal part, and substage $C$ being the state where several young leaflets have begun to grow (Fig. 2). Buds Nos. 8 and 12 were galls at substage $A$, Nos. 9 and 11 were galls at substage $B$, and No. 10 was a gall at substage $C$ (Fig. 3, right). From 10: 30 the buds were exposed to the attack of one parasitoid female. The first attack was observed at 10:45 on bud No. 9, and observation was continued until the parasitoid left the twig at $11: 57$.

Experiment II was carried out on April 5 with a 16 day-old parasitoid female in a

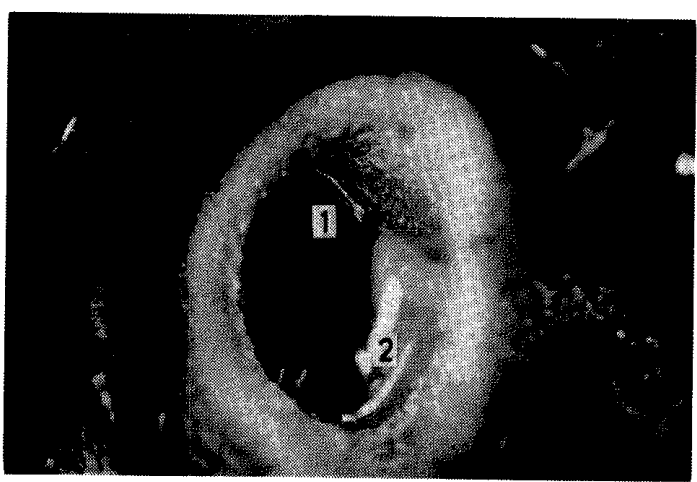

Fig. 1. A larval chamber of D. kuriphilus gall showing (1) a feeding-tube constructed by a female of $T$. beneficus for host-feeding and (2) a host larva.

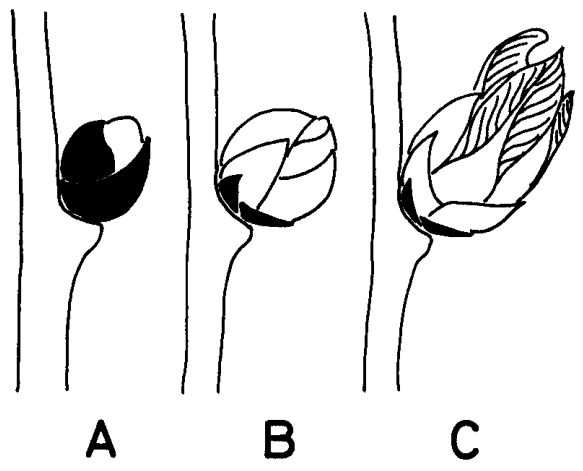

Fig. 2. Substages in the early stage of $D$. kuriphilus galls. A: substage $A$, where the gall has just begun to grow and remains largely covered with bud scales. B: substage $B$, where the gall is further grown and is covered with bud scales only on the basal part. C: substage $C$, where several young leaflets have begun to grow. 
Table 1. Gall measurements of the two experiments

\begin{tabular}{|c|c|c|c|c|c|c|}
\hline \multirow[b]{2}{*}{ Experiment } & \multirow[b]{2}{*}{ Bud No. } & \multirow[b]{2}{*}{ Substage } & \multicolumn{3}{|c|}{ Size $(\mathrm{mm})$} & \multirow{2}{*}{$\begin{array}{l}\text { No. of larval } \\
\text { chambers }\end{array}$} \\
\hline & & & $\begin{array}{l}\text { Width } \\
\text { (max) }\end{array}$ & $\begin{array}{l}\text { Width } \\
\text { (min) }\end{array}$ & Length & \\
\hline \multirow[t]{5}{*}{$\mathrm{I}$} & 8 & $\mathrm{~A}$ & 4.8 & 4.0 & 5.4 & 7 \\
\hline & 9 & B & 6.0 & 5.4 & 6.4 & 3 \\
\hline & 10 & C & 7.0 & 4.5 & 7.7 & 6 \\
\hline & 11 & $\mathrm{~B}$ & 5.0 & 4.5 & 7.2 & 3 \\
\hline & 12 & A & 4.5 & 4.0 & 5.0 & 7 \\
\hline \multirow[t]{5}{*}{ II } & 1 & B & 5.8 & 4.3 & 6.6 & 4 \\
\hline & 2 & $\mathrm{C}$ & 6.7 & 6.0 & 11.0 & 3 \\
\hline & 3 & $\mathrm{C}$ & 6.8 & 5.0 & 9.4 & 8 \\
\hline & 4 & $\mathrm{C}$ & 6.0 & 5.5 & 8.9 & 5 \\
\hline & 5 & $\mathrm{C}$ & 6.7 & 5.4 & 11.6 & 3 \\
\hline
\end{tabular}

room in which neither temperature nor humidity was controlled. A twig used in the experiment bore 5 galls in an early stage, of which the top one (No. 1) was at substage $B$ and others (Nos. 2-5) were at substage $C$ (Fig. 4, right). The observation began at 12: 30 when the third attack by the parasitoid female was detected on gall No. 1, and continued until 16:32 when the parasitoid left the twig. Other conditions were the same as those of the previous experiment.

After each observation, the galls were measured and dissected to examine the number of larval chambers in each gall, the number of parasitoid eggs deposited in each chamber and the traces of host-feeding. Table 1 shows the size of galls and number of the larval chambers in the galls on twigs in both experiments.

\section{RESULTS}

In experiment $\mathrm{I}$, as shown in Fig. 3, the parasitoid female searched two buds, Nos. 8 and 9, and stung them 9 times. She stayed on bud No. 9 for 4,050 sec $(67 \mathrm{~min}$ and $30 \mathrm{sec})$, where she stung the gall 6 times for a total of $3,670 \mathrm{sec}(61 \mathrm{~min}$ and $10 \mathrm{sec})$. The time elapsed for searching (drumming with antennae), resting and walking was only $380 \mathrm{sec}(6 \mathrm{~min}$ and $20 \mathrm{sec})$. She then moved to bud No. 8 where she stayed for $215 \mathrm{sec}$ ( $3 \mathrm{~min}$ and $35 \mathrm{sec}$ ) and stung 3 times for $130 \mathrm{sec}(2 \mathrm{~min}$ and $10 \mathrm{sec})$. Then she walked out toward the twig. After $15 \mathrm{sec}$, she returned again to bud No. 8, stayed on it for $20 \mathrm{sec}$, then moved to bud No. 9 and stayed there for $20 \mathrm{sec}$. Then she walked toward the top bud (No. 1) drumming the surface of the twig and buds with her antennae, and left the twig after preening her ovipositor with her hindlegs.

Dissection of the galls stung by the parasitoid (buds Nos. 8 and 9) revealed one parasitoid egg in each of two chambers in gall No. 9, but none in any chambers of gall No. 8.

In experiment II, the parasitoid female searched three upper buds (Nos. 1, 2 and 3) and stung them 25 times during the observation. Since she had stung bud No. 1 twice before the observation began, she actually stung a total of 27 times. Host-feeding was observed twice on bud No. 1 as shown in Fig. 4.

The parasitoid first stayed on bud No. 1 for more than $11,225 \mathrm{sec}$ (more than three hours), during which she stung the gall 13 times for more than a total of 4,635 sec (77 

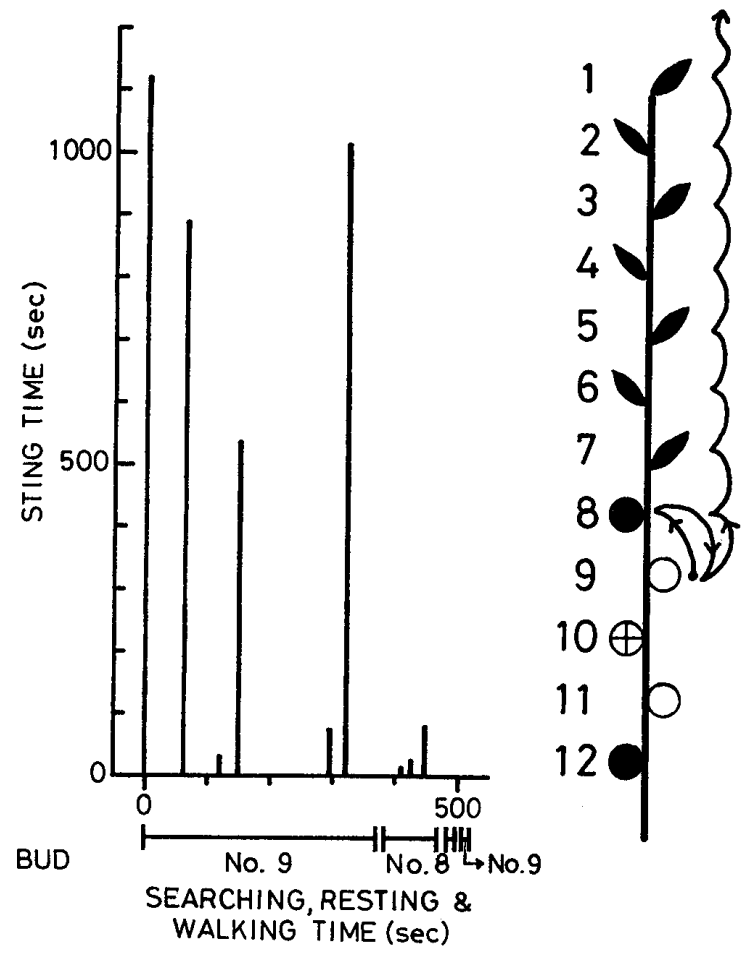

Fig. 3. Behavioural sequence of a female of $T$. beneficus in experiment I. Solid spindles: healthy buds, solid circles : galls at substage $A$, open circles : galls at substage $B$, open circle with cross : gall at substage $C$.

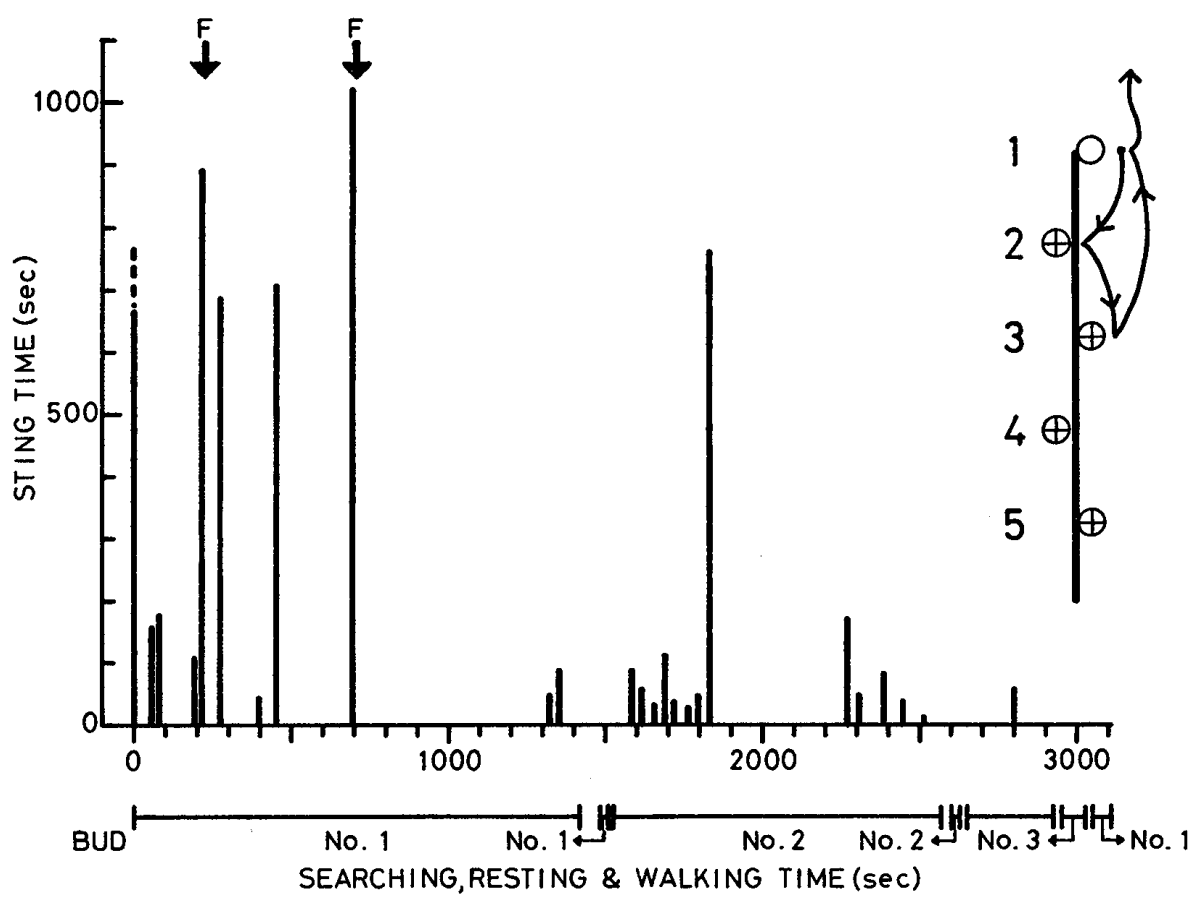

Fig. 4. Behavioural sequence of a female of $T$. beneficus in experiment II. F: host-feeding. For gall substages see legend of Fig. 3. 
min and $15 \mathrm{sec})$ and did host-feeding twice for $3,870 \mathrm{sec}(64 \mathrm{~min}$ and $30 \mathrm{sec})$ and 1,300 $\mathrm{sec}(21 \mathrm{~min}$ and $40 \mathrm{sec})$, respectively. After the second host-feeding, a long preening $(170 \mathrm{sec})$ followed, and she then repeated searching and resting $(460 \mathrm{sec})$. A total of more than 1,420 sec (23 min and $40 \mathrm{sec}$ ) elapsed on the gall during her searching, resting and walking. Then she moved from the gall, and rested on the twig $5 \mathrm{~mm}$ under the gall for $65 \mathrm{sec}$. After this she searched on bud No. 1 again for $25 \mathrm{sec}$, then moved to gall No. 2.

On bud No. 2, the parasitoid female stayed for 2,600 sec (43 min and $20 \mathrm{sec}$ ), stinging the gall 13 times for a total of $1,540 \mathrm{sec}(25 \mathrm{~min}$ and $40 \mathrm{sec})$. After one lengthy sting $(755 \mathrm{sec})$, she searched for a long time $(440 \mathrm{sec})$ on the gall. She then repeated probing and searching, then walked on the twig toward bud No. 1, but returned to bud No. 2 and searched there again for $30 \mathrm{sec}$. Then she walked toward bud No. 3, where she stayed for only $340 \mathrm{sec}(5 \mathrm{~min}$ and $40 \mathrm{sec}$ ), stinging the gall once for $60 \mathrm{sec}$. After a short upward walk on the twig, she returned to bud No. 3, where she walked and preened her wings for $65 \mathrm{sec}$. She then walked toward the top bud (No. 1) and flew away after resting on it for a short time $(60 \mathrm{sec})$.

Results of the dissection of galls stung by the parasitoid were as follows: among four larval chambers in the gall of bud No. 1, two parasitoid eggs were found in one chamber and three in another. In another chamber a host cynipid larva withered by hostfeeding was found but there were no parasitoid eggs. Nor were eggs found in any chambers of the other two galls of buds Nos. 2 and 3. However, one of the three chambers in gall No. 2 contained a paralysed host larva.

\section{DISCUSSION}

Throughout the two experiments, the stinging behaviour was observed 34 times (9 times in experiment I and 25 in experiment II). The sting is clearly classified by its length of time into two categories, shorter (less than $200 \mathrm{sec}$ ) and longer (more than $500 \mathrm{sec}$ ) stings. The former may be a sting to probe the gall but the latter is considered to be either a sting to paralyse the host larva and oviposit, to probe host larva in the larval chamber or to construct a feeding-tube.

The longer sting was observed four times on gall No. 9 at substage $B$ in experiment $\mathrm{I}$, and two eggs (one in each of two chambers) were deposited in the gall. Therefore, two possible speculations are made. One is that two of the four stings are for oviposition, and two others for paralysing hosts. The other may be that the parasitoid accomplished both paralysation and oviposition in one sting; thus two of the four stings were for paralysation and oviposition, and with the two other stings she probed host larvae but did not oviposit because the hosts were unsuitable.

In experiment II, the longer sting was observed five times on gall No. 1 at substage $B$ and once on gall No. 2 at substage $C$. While the host-feeding behaviour was observed twice on the former gall, a trace of the feeding was found in only one larval chamber of that gall. Therefore, it is supposed that two occurrences of host-feeding observed on the gall were made against the same host larva and that two longer stings immediately before the host-feedings were for constructing feeding-tubes. Since parasitoid eggs were deposited in two other chambers, two of the three other longer stings on the gall are supposed to have been for oviposition and one for probing a host larva. The parasitoid female may deposit two or more eggs in the same larval chamber at one sting, 
Table 2. Length of time taken by a parasitoid female for each oviposition, host-feeding and feeding-tube construction

\begin{tabular}{cccc}
\hline Behaviour & $\begin{array}{c}\text { Length of } \\
\text { time }(\mathrm{sec})\end{array}$ & Experiment & Bud No. \\
\hline Oviposition or probing host larva & 1,120 & I & 9 \\
& 890 & I & 9 \\
& 540 & I & 9 \\
& 1,015 & I & 1 \\
Construction of feeding-tube & $>670$ & II & 1 \\
& 690 & II & 1 \\
Host-feeding & 710 & II & 2 \\
& 1,025 & II & 1 \\
\end{tabular}

Table 3. Observed time for each component of behaviour of the parasitoid female

\begin{tabular}{lccccc}
\hline \multicolumn{1}{c}{ Component } & \multicolumn{2}{c}{ Experiment I } & & \multicolumn{2}{c}{ Experiment II } \\
\cline { 2 - 3 } \cline { 5 - 6 } \cline { 5 - 6 } & $\begin{array}{c}\text { Total time } \\
(\mathrm{sec})\end{array}$ & $\begin{array}{c}\text { Rate } \\
(\%)\end{array}$ & & $\begin{array}{c}\text { Total time } \\
(\mathrm{sec})\end{array}$ & $\begin{array}{c}\text { Rate } \\
(\%)\end{array}$ \\
\hline Walking, searching, resting and preening & 520 & 12.0 & & 3,105 & $21.4(41.9)^{\mathrm{a}}$ \\
Probing gall (shorter sting <200 sec) & 235 & 5.4 & & 1,490 & $10.3(20.1)$ \\
Oviposition or probing host larva & 3,565 & 82.5 & & 2,825 & $19.5(38.1)$ \\
Construction of feeding-tube & 0 & 0 & & 1,920 & 13.2 \\
Host-feeding & 0 & 0 & & 5,170 & 35.6
\end{tabular}

a Rates in parentheses refer to those times excluded for construction of feeding-tube and for hostfeeding.

because two eggs were found in one chamber and three eggs in another. Although two speculations were made in experiment I, the results of experiment II may indicate that the parasitoid accomplished both paralysation and oviposition in one sting.

The occurrence of one longer sting without oviposition on gall No. 2 suggests that the parasitoid female paralysed the host larva but did not oviposit in the larval chamber. When field galls are collected and dissected, larval chambers with a paralysed host larva are found but the parasitoid eggs are never found in some chambers. For example, Murakami (1981 a) showed data that in 7 larval chambers, or $1.8 \%$ of 380 in 119 examined galls collected on Mt. Aburayama, Fukuoka from April 17 to May 1, 1977, the host larvae were paralysed but no parasitoid eggs were deposited (Table 3 in Murakami, 1981 a).

Table 2 shows the length of time that the parasitoid females required for one oviposition, for construction of one feeding-tube and for one host-feeding. The period for one oviposition or probing of a host larva ranged between $540 \mathrm{sec}(9 \mathrm{~min})$ and 1,120 $\mathrm{sec}(18 \mathrm{~min}$ and $40 \mathrm{sec})$ averaging approximately $820 \mathrm{sec}(13 \mathrm{~min}$ and $40 \mathrm{sec})$. Average time required for constructing a feeding-tube was $960 \mathrm{sec}(16 \mathrm{~min})$ and it was slightly longer than that for oviposition. However, host-feeding took much longer than sting time. 
The time-allocation for each component of behaviour differed between experiments. Total time allocated for each component and its rate during observations is shown in Table 3. The rate was variable, probably due to the following factors: age of the parasitoid females, stage of host galls, number of larval chambers per gall, number of buds and galls on the twigs and/or temperature condition when the experiments were conducted. The reason the female examined in experiment I did no host-feeding may be that she was relatively young ( 9 day-old) and therefore did not need to obtain protein for ovigenesis by such feeding. On the contrary, the older female (16 day-old) examined in experiment II needed host-feeding twice during so long a time for ovigenesis. The rate of walking, searching, resting and preening times was much longer in experiment II than in experiment I. This is due to a long preening $(170 \mathrm{sec})$ immediately after the second host-feeding, and the subsequent repeated searching and resting on gall No. 1 ( $460 \mathrm{sec})$, as well as a long search $(440 \mathrm{sec})$ after a longer sting on gall No. 2 (Fig. 4).

Both the parasitoid females used in the present experiments oviposited only in galls at substage $B$ (No. 9 in experiment I and No. 1 in experiment II). These were the first encountered by each female. In the gall at substage $A$, the female probed three times and searched for a total of $105 \mathrm{sec}$ on bud No. 8 in experiment I, but she did neither longer sting nor oviposition on the gall. This means that a parasitoid female does not care for such a young gall for oviposition. On the contrary, a gall in substage $C$ is rather preferable. Gall No. 2 at this stage was stung once for a long time though it was not oviposited, and the parasitoid stayed there for 2,600 sec in experiment II.

The rate of oviposition was calculated as 1.67 and 1.24 eggs per hour in experiments I and II, respectively. The real rate of oviposition per day may depend on the interval of serial oviposition activities, the age of the parasitoid, the potential for encountering an available host gall (parasitoid and gall densities as well as their spatial distributions) and physical conditions. Further experiments are necessary to determine the real rate of oviposition of this parasitoid.

\section{REFERENCES}

Murakami, Y. (1981 a) The parasitoids of Dryocosmus kuriphilus Yasumatsu (Hymenoptera: Cynipidae) in Japan and the introduction of a promising natural enemy from China (Hymenoptera: Chalcidoidea). J. Fac. Agr., Kyushu Univ. 25: 167-174.

Murakami, Y. (1981 b) Comparison of the adult emergence period between Torymus (Syntomaspis) beneficus, a native parasitoid of the chestnut gall wasp and a congeneric parasitoid imported from China (Hymenoptera: Torymidae). Proc. Assoc. Plant Prot. Kyushu 27: 156-158 (in Japanese with an English summary).

Tokunisa, E. (1979) Synchronization of oviposition period of Torymus (Syntomaspis) sp. with vulnerable gall stage of the chestnut gall wasp, Dryocosmus kuriphilus Yasumatsu. Proc. Assoc. Plant Prot. Kyushu 25: 150-153 (in Japanese with an English summary).

Yasumatsu, K. and K. Kamijo (1979) Chalcidoid parasites of Dryocosmus kuriphilus Yasumatsu (Cynipidae) in Japan, with descriptions of five new species (Hymenoptera). Esakia 14: 93-111. 